\title{
A Palaeolithic diet improves glucose tolerance more than a Mediterranean-like diet in individuals with ischaemic heart disease
}

\author{
S. Lindeberg • T. Jönsson • Y. Granfeldt • \\ E. Borgstrand • J. Soffman • K. Sjöström • B. Ahrén
}

Received: 1 May 2007 / Accepted: 4 May 2007 / Published online: 22 June 2007

(C) Springer-Verlag 2007

\begin{abstract}
Aims/hypothesis Most studies of diet in glucose intolerance and type 2 diabetes have focused on intakes of fat, carbohydrate, fibre, fruits and vegetables. Instead, we aimed to compare diets that were available during human evolution with more recently introduced ones.

Methods Twenty-nine patients with ischaemic heart disease plus either glucose intolerance or type 2 diabetes were randomised to receive (1) a Palaeolithic ('Old Stone Age') diet $(n=14)$, based on lean meat, fish, fruits, vegetables, root vegetables, eggs and nuts; or (2) a Consensus (Mediterranean-like) diet $(n=15)$, based on whole grains, low-fat dairy products, vegetables, fruits, fish, oils and margarines. Primary outcome variables were changes in weight, waist circumference and plasma glucose AUC (AUC Glucose ${ }_{0-120}$ ) and plasma insulin AUC (AUC Insulin ${ }_{0-120}$ ) in OGTTs. Results Over 12 weeks, there was a $26 \%$ decrease of AUC Glucose $_{0-120}(p=0.0001)$ in the Palaeolithic group and a $7 \%$ decrease $(p=0.08)$ in the Consensus group. The larger $(p=$ $0.001)$ improvement in the Palaeolithic group was independent $(p=0.0008)$ of change in waist circumference $(-5.6 \mathrm{~cm}$ in the Palaeolithic group, $-2.9 \mathrm{~cm}$ in the Consensus group;
\end{abstract}

Electronic supplementary material The online version of this article (doi:10.1007/s00125-007-0716-y) contains supplementary material, which is available to authorised users.

S. Lindeberg $(\bowtie) \cdot$ T. Jönsson $\cdot$ E. Borgstrand $\cdot$ J. Soffman •

K. Sjöström $\cdot$ B. Ahrén

Department of Medicine, Hs 32, University of Lund,

SE-221 85 Lund, Sweden

e-mail: staffan.lindeberg@med.lu.se

Y. Granfeldt

Department of Applied Nutrition and Food Chemistry,

University of Lund,

Lund, Sweden $p=0.03$ ). In the study population as a whole, there was no relationship between change in AUC Glucose $_{0-120}$ and changes in weight $(r=-0.06, p=0.9)$ or waist circumference $(r=0.01, p=1.0)$. There was a tendency for a larger decrease of AUC Insulin ${ }_{0-120}$ in the Palaeolithic group, but because of the strong association between change in AUC Insulin $n_{0-120}$ and change in waist circumference $(r=0.64, p=0.0003)$, this did not remain after multivariate analysis.

Conclusions/interpretation A Palaeolithic diet may improve glucose tolerance independently of decreased waist circumference.

Keywords Diet - Evolution - Glucose intolerance . Ischaemic heart disease · Palaeolithic diet - Type 2 diabetes

$\begin{array}{ll}\text { Abbreviations } \\ \text { BIA } & \begin{array}{l}\text { bioelectrical impedance analysis } \\ \text { percentage of total energy intake } \\ \text { homeostasis model assessment } \\ \text { E\% }\end{array} \\ \text { HOMA-Insulin resistance } \\ \text { IFG } & \begin{array}{l}\text { impaired fasting glucose } \\ \text { impaired glucose tolerance }\end{array} \\ \text { IGT } & \begin{array}{l}\text { ischaemic heart disease } \\ \text { IHD }\end{array} \\ \text { NGT } & \text { normal glucose tolerance }\end{array}$

Introduction

Impaired glucose tolerance (IGT) and type 2 diabetes are common risk factors for ischaemic heart disease (IHD) [1, 2], which negatively affect the long-term prognosis after myocardial infarction $[3,4]$. In fact, cross-sectional studies have found only $35-54 \%$ of IHD patients have normal glucose tolerance (NGT) [5-11]. Increased physical activity, 
healthy food choices and decreased waist circumference may help to lower the rate of progression from IGT to diabetes [12-14]. Standard dietary advice for patients with IHD and/ or IGT generally includes whole-grain cereals, low-fat dairy products, vegetables, fruits, legumes, oily fish and refined fats that are rich in monounsaturated fatty acids and alphalinolenic acid while low in trans-unsaturated fatty acids [1517]. However, the optimal dietary treatment of IGT and insulin resistance is a matter of debate, including the preferred amounts and types of fat, carbohydrate and protein $[16,18-21]$, and amounts of fruits [22] and sodium [23, 24].

Since nutritional science is hampered by confounders, an evolutionary approach has been suggested. It is postulated that foods that were regularly eaten during primate and human evolution, in particular during the Palaeolithic (the 'Old Stone Age,' 2.5-0.01 million years BP), may be optimal to prevent insulin resistance and glucose intolerance $[25,26]$. A Palaeolithic diet includes lean meat, fish, shellfish, fruits, vegetables, roots, eggs and nuts, but not grains, dairy products, salt or refined fats and sugar, which became staple foods long after the appearance of fully modern humans. We found that traditional Pacific Islanders of Kitava, Papua New Guinea, had no signs of IHD, stroke or markers of the metabolic syndrome, possibly because of their traditional lifestyle [27-29]. In the present study, we examined the effect of dietary advice according to this Palaeolithic diet model on glucose tolerance and postchallenge insulin response in glucose-intolerant IHD patients recruited from a Coronary Care Unit, compared with dietary advice according to standard clinical practice. Our hypothesis was that the Palaeolithic diet would provide metabolic benefits beyond its nutrient composition.

\section{Materials and methods}

Participants The study was a 12 week controlled dietary intervention trial in 29 (out of 38 eligible) male IHD patients with waist circumference $>94 \mathrm{~cm}$ and increased blood glucose or known diabetes, recruited from the Coronary Care Unit at Lund University Hospital, Sweden. We included patients with any of the following conditions: an ongoing acute coronary syndrome, a history of myocardial infarction diagnosed by creatine kinase MB isoenzyme or troponin elevation, percutaneous coronary intervention or coronary artery bypass surgery or angiographically diagnosed coronary stenosis $\geq 30 \%$. Exclusion criteria were BMI $<20 \mathrm{~kg} / \mathrm{m}^{2}$, serum creatinine $>130 \mu \mathrm{mol} / \mathrm{l}$, poor general condition, dementia, unwillingness/inability to prepare food at home, participation in another medical trial, chronic inflammatory bowel disease, type 1 diabetes and treatment with hypoglycaemic agents, warfarin or oral steroids. Other drugs were not restricted, and treatment with statins and beta blockers was usually initiated and/or changed during the trial. Approval for the study was obtained from the regional Medical Ethics Committee, and all individuals gave written informed consent to participate in the study. In addition to the 29 patients who completed the trial, nine randomised subjects were excluded for the following reasons: worsening general condition $(n=4)$, unwillingness to continue $(n=3$, all in the Palaeolithic group) or missing OGTT data (one in each group).

Procedure All eligible subjects were informed of the intention to compare two healthy diets and that it was unknown if either of them would be superior to the other with regard to weight reduction and improved glucose metabolism. Patients qualified for the study if they had known type 2 diabetes or, at a screening OGTT with $75 \mathrm{~g}$ glucose, a fasting capillary blood glucose $\geq 6.1 \mathrm{mmol} / \mathrm{l}$ or a $2 \mathrm{~h}$ capillary blood glucose $\geq 7.8 \mathrm{mmol} / 1$. In 13 subjects, this screening OGTT was performed after an acute coronary episode (Table 1). The remaining 16 subjects, eight in each group, were recruited between 2 months and 2 years after hospital discharge. Blood glucose concentrations were analysed in capillary whole blood immediately after collection with a HemoCue photometer (HemoCue, Ängelholm, Sweden). A second OGTT was performed within 2 weeks, when venous plasma samples were collected $<5 \mathrm{~min}$ before and 30 and $120 \mathrm{~min}$ after ingestion of $75 \mathrm{~g}$ of glucose and analysed for glucose by the glucose oxidase technique and for insulin by RIA (Linco Research, St Charles, MO, USA). Normal plasma glucose was defined as a fasting venous plasma glucose $<6.1 \mathrm{mmol} / 1$ and a $2 \mathrm{~h}$ venous plasma glucose $<7.8 \mathrm{mmol} / \mathrm{l}$. IGT was defined as $2 \mathrm{~h}$ plasma glucose of $7.9-11.0 \mathrm{mmol} / \mathrm{l}$ and fasting plasma glucose $<7 \mathrm{mmol} / \mathrm{l}$, and diabetic levels as fasting plasma glucose $\geq 7.0 \mathrm{mmol} / \mathrm{l}$ or $2 \mathrm{~h}$ plasma glucose $\geq 11.1 \mathrm{mmol} / \mathrm{l}$. Impaired fasting glucose (IFG) was defined as a fasting plasma glucose 6.1-6.9 $\mathrm{mmol} / \mathrm{l}$ and a $2 \mathrm{~h}$ venous plasma glucose $<7.8 \mathrm{mmol} / \mathrm{l}$.

Diets Immediately after the second OGTT, subjects were randomised to one of two healthy diets: (1) a Consensus (Mediterranean-like) diet $(n=15)$ based on whole-grain cereals, low-fat dairy products, potatoes, legumes, vegetables, fruits, fatty fish and refined fats rich in monounsaturated fatty acids and alpha-linolenic acid; or (2) a Palaeolithic diet $(n=14)$ based on lean meat, fish, fruits, leafy and cruciferous vegetables, root vegetables (including restricted amounts of potatoes), eggs and nuts. All subjects were never-smokers or ex-smokers (Table 1), five of whom had stopped smoking $\leq 2$ weeks prior to study start (three in the Palaeolithic group and two in the Consensus group). The others had stopped smoking $>6$ months ago.

All subjects were informed individually (by S. Lindeberg, K. Sjöström or E. Borgstrand) during two $1 \mathrm{~h}$ sessions and 
Table 1 Patient characteristics at baseline
Values are means \pm SD for all continuous variables except C-reactive protein, for which values are geometric means (ranges)

${ }^{\text {a }}$ For difference between groups

${ }^{\mathrm{b}}<1$ week between acute coronary syndrome (myocardial infarction and/or percutaneous coronary intervention) and dietary intervention

\begin{tabular}{|c|c|c|c|}
\hline & \multicolumn{2}{|l|}{ Group } & \multirow[t]{2}{*}{$p$ value $^{\mathrm{a}}$} \\
\hline & Palaeolithic $(n=14)$ & Consensus $(n=15)$ & \\
\hline Age (years) & $65 \pm 10$ & $57 \pm 7$ & 0.01 \\
\hline Weight $(\mathrm{kg})$ & $92 \pm 11$ & $96 \pm 12$ & 0.3 \\
\hline BMI $\left(\mathrm{kg} / \mathrm{m}^{2}\right)$ & $29 \pm 4$ & $30 \pm 2$ & 0.3 \\
\hline Waist (cm) & $106 \pm 8$ & $107 \pm 8$ & 0.8 \\
\hline Fasting plasma glucose $(\mathrm{mmol} / \mathrm{l})$ & $6.8 \pm 1.3$ & $7.1 \pm 1.8$ & 0.6 \\
\hline $2 \mathrm{~h}$ plasma glucose $(\mathrm{mmol} / \mathrm{l})$ & $8.9 \pm 1.8$ & $8.8 \pm 3.8$ & 1.0 \\
\hline Glucose AUC (mmol/1×min) & $1,104 \pm 116$ & $1,145 \pm 298$ & 0.6 \\
\hline $\mathrm{HbA}_{1 \mathrm{c}}(\%)$ & $4.8 \pm 0.3$ & $4.9 \pm 0.8$ & 0.6 \\
\hline IFG/IGT/diabetes (capillary), $n$ & $2 / 10 / 3$ & $3 / 9 / 5$ & 0.7 \\
\hline IFG/IGT/diabetes (OGTT), $n$ & $0 / 2 / 10$ & $2 / 4 / 9$ & 0.7 \\
\hline Fasting plasma insulin (pmol/1) & $102 \pm 36$ & $123 \pm 68$ & 0.3 \\
\hline $2 \mathrm{~h}$ plasma insulin $(\mathrm{pmol} / \mathrm{l})$ & $988 \pm 570$ & $674 \pm 532$ & 0.14 \\
\hline In HOMA-IR & $0.62 \pm 0.38$ & $0.75 \pm 0.53$ & 0.5 \\
\hline Insulin AUC (nmol/1× min) & $81 \pm 41$ & $70 \pm 45$ & 0.5 \\
\hline Systolic blood pressure $(\mathrm{mmHg})$ & $132 \pm 12$ & $129 \pm 19$ & 0.6 \\
\hline Diastolic blood pressure (mmHg) & $77 \pm 9$ & $78 \pm 11$ & 0.7 \\
\hline Serum cholesterol (mmol/l) & $4.2 \pm 0.6$ & $4.5 \pm 0.9$ & 0.3 \\
\hline Serum triacylglycerols $(\mathrm{mmol} / \mathrm{l})$ & $1.3 \pm 0.6$ & $1.9 \pm 0.8$ & 0.06 \\
\hline C-reactive protein $(\mu \mathrm{g} / \mathrm{ml})$ & $4.5(0.8-88)$ & $4.5(0.8-43)$ & 1.0 \\
\hline \multicolumn{4}{|l|}{ Study start $<2$ weeks } \\
\hline After acute coronary syndrome ${ }^{\mathrm{b}}(n)$ & 6 & 7 & 0.8 \\
\hline Number of days & $4 \pm 2$ & $4 \pm 2$ & 1.0 \\
\hline After statin treatment initiated $(n)$ & 6 & 6 & 0.9 \\
\hline After quitting smoking $(n)$ & 2 & 1 & 0.8 \\
\hline No statin treatment $(n)$ & 1 & 2 & 0.9 \\
\hline Smoking: never/ex- $(n)$ & $5 / 9$ & $4 / 11$ & 0.7 \\
\hline
\end{tabular}

Care Unit. Since the required increase in education intensity in order to match the Palaeolithic group was rather small, no 'usual care' control group was considered necessary. Advice about regular physical activity was given equally to the two groups. Both groups were advised not to consume more than one glass of wine per day.

Evaluation Changes in the AUC between 0 and $120 \mathrm{~min}$ during OGTT for plasma glucose (AUC Glucose ${ }_{0-120}$ ) and plasma insulin (AUC Insulin ${ }_{0-120}$ ) were predefined primary endpoints, along with changes in body weight and waist circumference. The base of the AUC was set at $0 \mathrm{mmol} / \mathrm{l}$ for glucose and $0 \mathrm{pmol} / 1$ for insulin. The computer-generated homeostasis model assessment of insulin resistance (HOMA-IR) index, which has been suggested to provide a reasonable estimate of insulin resistance, was derived from fasting plasma glucose and insulin (www.dtu.ox.ac.uk) [34]. The early phase of post-challenge glucose and insulin responses were represented by the AUCs (Incremental AUC Glucose ${ }_{0-30}$ and Incremental AUC Insulin ${ }_{0-30}$ ) during the first $30 \mathrm{~min}$ of the OGTT, using levels at $0 \mathrm{~min}$ as the base of the area.

A 4 day weighed food record on four consecutive days, including one weekend day, with weighing of each food item on a digital weighing scale (that could be set to zero), was completed by the participants, starting $15 \pm 5$ days after
The type of dietary advice given to the Consensus group was similar to the established programme at the Coronary 
Table 2 Primary outcome variables

Consensus $(n=15)$

Group

Palaeolithic $(n=14)$

Weight (kg)

Baseline

6 weeks

Change 0-6 weeks

95\% CI

$p$ value for change within group

12 weeks

Change 6-12 weeks

95\% CI

$p$ value for change within group

Change 0-12 weeks

$95 \% \mathrm{CI}$

$p$ value for change within group

Waist circumference $(\mathrm{cm})$

Baseline

6 weeks

Change 0-6 weeks

$95 \% \mathrm{CI}$

$p$ value for change within group

12 weeks

Change 6-12 weeks

$95 \%$ CI

$p$ value for change within group

Change 0-12 weeks

\section{$95 \% \mathrm{CI}$}

$p$ value for change within group

AUC $^{\mathrm{b}}$ Glucose $_{0-120}(\mathrm{mmol} / \mathrm{l} \times \min )$

Baseline

6 weeks

Change 0-6 weeks

95\% CI

$p$ value for change within group

12 weeks

Change 6-12 weeks

$95 \%$ CI

$p$ value for change within group

Change 0-12 weeks

$95 \% \mathrm{CI}$

$p$ value for change within group

AUC $^{\mathrm{b}}$ Insulin $_{0-120}(\mathrm{nmol} / 1 \times \min )$

Baseline

6 weeks

Change 0-6 weeks

95\% CI

$p$ value for change within group

12 weeks

Change 6-12 weeks

$95 \%$ CI

$p$ value for change within group

Change 0-12 weeks

$95 \% \mathrm{CI}$

$p$ value for change within group

$$
\begin{aligned}
& 91.7 \pm 11.2 \\
& 88.0 \pm 10.7 \\
& -3.7 \pm 2.2 \\
& -4.9 \text { to }-2.4 \\
& 0.0001 \\
& 86.7 \pm 11.3 \\
& -1.4 \pm 2.1 \\
& -2.6 \text { to }-0.1 \\
& 0.03 \\
& -5.0 \pm 3.3 \\
& -6.9 \text { to }-3.1 \\
& 0.0001
\end{aligned}
$$

$105.8 \pm 7.6$

$102.8 \pm 7.8$

$-3.0 \pm 1.8$

-4.0 to -2.0

0.0001

$100.2 \pm 7.7$

$-2.6 \pm 2.4$

-3.9 to -1.2

0.001

$-5.6 \pm 2.8$

-7.2 to -3.9

0.0001

$1,104 \pm 118$

$877 \pm 161$

$-220 \pm 206$

-339 to -101

0.002

$807 \pm 107$

$-70 \pm 156$

$-160 ;+20$

0.12

$-290 \pm 143$

-373 to -208

0.0001

$80.5 \pm 41.1$

$63.1 \pm 30.0$

$-17.4 \pm 27.7$

-33.4 to -1.3

0.04

$56.1 \pm 30.1$

$-7.0 \pm 16.9$

-16.7 to +2.8

0.15

$-24.3 \pm 28.4$

-40.7 to -8.0

0.007

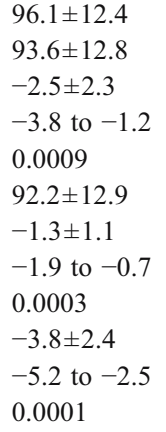

$96.1 \pm 12.4$

$93.6 \pm 12.8$

$-2.5 \pm 2.3$

-3.8 to -1.2

0.0009

$92.2 \pm 12.9$

$-1.3 \pm 1.1$

-1.9 to -0.7

0.0003

$-3.8 \pm 2.4$

-5.2 to -2.5

0.0001

$106.6 \pm 8.0$

$105.2 \pm 8.8$

0.8

$-1.5 \pm 2.0$

-2.7 to -0.2

0.02

$103.6 \pm 8.6$

$-1.5 \pm 1.8$

-2.7 to -0.7

0.003

$-2.9 \pm 3.1$

-4.8 to -1.1

0.004

$1,145 \pm 298$

0.6

$1,024 \pm 339$

$-120 \pm 255$

-262 to +21

0.09

$1,065 \pm 250$

$+41 \pm 179$

$-59 ;+140$

0.4

$-80 \pm 168$

0.001

-173 to +13

0.09

$69.7 \pm 44.7$

$54.1 \pm 37.2$

$-15.5 \pm 16.9$

0.5

0.5

0.8

-24.9 to -6.2

0.003

$60.4 \pm 46.4$

0.8

$+6.2 \pm 25.8$

-8.1 to +20.5

0.4

$-9.3 \pm 23.3$

-22.2 to +3.6

0.14

0.3

0.2

0.2

0.2

0.9
Values are means $\pm \mathrm{SD}$

${ }^{\mathrm{a}}$ For difference between groups

${ }^{\mathrm{b}}$ AUC for glucose and insulin response to a $75 \mathrm{~g}$ OGTT. The base of the AUC was set at $0 \mathrm{mmol} / \mathrm{l}$ for glucose and $0 \mathrm{nmol} / \mathrm{l}$ for insulin. 
initiating the dietary change. Nutrients were calculated using Matsedel dietary analysis software (Kost och Näringsdata AB, Bromma, Sweden). Glycaemic load was calculated by multiplying the content of available carbohydrate in the serving of each food by the food's Glycaemic Index (with glucose as the reference) as given by Foster-Powell et al. [35]. Under-reporting was checked for by comparing food records with baseline weight and achieved weight loss, and by evaluating distribution and amount of consumed food. Body composition was estimated in a subset of 15 patients by use of leg-to-leg bioelectrical impedance analysis (BIA), using a Tanita Body Fat Analyzer (Model TBF 105; Tanita Corporation of America, Arlington Heights, IL, USA).

Statistics A pre-study power calculation showed that 12 subjects would be needed in each group in order to detect, with $80 \%$ power and at a significance level of $5 \%$, a $20 \%$ reduction in AUC Glucose $\mathrm{C}_{0-120}$. Group assignment was made by use of minimisation, a restricted randomisation procedure which lowers the risk of baseline differences [36], using diabetes at screening (no/yes) and BMI (below or above $27 \mathrm{~kg} / \mathrm{m}^{2}$ ) as restricting variables. A two-way paired $t$ test was used to analyse within-subject differences in absolute values, while a two-way unpaired $t$ test and repeated-measures ANOVA were used to analyse betweensubject differences in these changes. Simple and multiple linear regression was used to analyse univariate and bivariate relationships. All variables showed reasonable normal distribution in normal plots, but change in AUC Glucose $_{0-120}$, HOMA-IR and fruit intake showed perfect normal distribution only after $\ln$ transformation.

\section{Results}

The two groups differed at baseline only with regard to age being higher $(p=0.01)$ and plasma triacylglycerols being lower $(p=0.06)$ in the Palaeolithic group (Table 1). There was no relationship between age and any of the outcome variables at study start (Supplementary Tables 2, 3, 4, 5 and 6). During the 12 week dietary intervention, both groups decreased their waist circumference with a greater decrease in the Palaeolithic group ( $p=0.03$; Table 2$)$. Weight loss was on average $4.4 \mathrm{~kg}$ with no significant group difference.

In the Palaeolithic group, there was a $20 \%$ decrease in the OGTT AUC Glucose ${ }_{0-120}$ during the first 6 weeks $(p=0.0001)$, and an $8 \%$ decrease between weeks 6 and 12 $(p=0.12$; Figs 1 and 2, Table 2). In the Consensus group, a $10 \%$ decrease of AUC Glucose ${ }_{0-120}$ was seen after the first 6 weeks $(p=0.09)$ with no further change at 12 weeks $(+4 \%, p=0.4)$, despite a further decrease of weight $(p=$ $0.0003)$ and waist circumference $(p=0.003)$. In the whole study population, there was no relationship between change in AUC Glucose ${ }_{0-120}$ and changes in weight $(r=-0.06, p=$ $0.9)$ or waist circumference $(r=0.01, p=1.0)$ during the whole study period (Supplementary Table 6), which, consequently, did not explain the larger improvement of AUC Glucose ${ }_{0-120}$ in the Palaeolithic group (Supplementary Table 2).

In each group, AUC Insulin ${ }_{0-120}$, decreased during the first 6 weeks by $22 \%$, but the decrease over 12 weeks was significant only in the Palaeolithic group (Table 2, Fig. 3). After adjustment for waist loss, the tendency for a larger decrease of AUC Insulin ${ }_{0-120}$ in the Palaeolithic group was no longer significant (Supplementary Table 3). Among the two groups combined, there was no association between change in AUC Glucose ${ }_{0-120}$ and change in AUC Insulin $_{0-120}(r=$ $0.19, p=0.3$ ), and thus the group difference in improvement of AUC Glucose ${ }_{0-120}$ was independent of changes in AUC Insulin $_{0-120}(p=0.002)$ or In HOMA-IR ( $p=0.0009$; Supplementary Table 2).

Among secondary outcome variables, the most marked change was a $36 \%$ decrease in $2 \mathrm{~h}$ plasma glucose in the Palaeolithic group (from 8.9 to $5.6 \mathrm{mmol} / \mathrm{l}, p=0.0003$; Table 3 ). In contrast, $2 \mathrm{~h}$ plasma glucose decreased by only
Fig. 1 Plasma glucose during OGTTs at study start (baseline, closed circles) and after 12 weeks (open circles) in the Palaeolithic (a) and Consensus (b) groups. Values are means \pm SE. $* * * p<0.001$
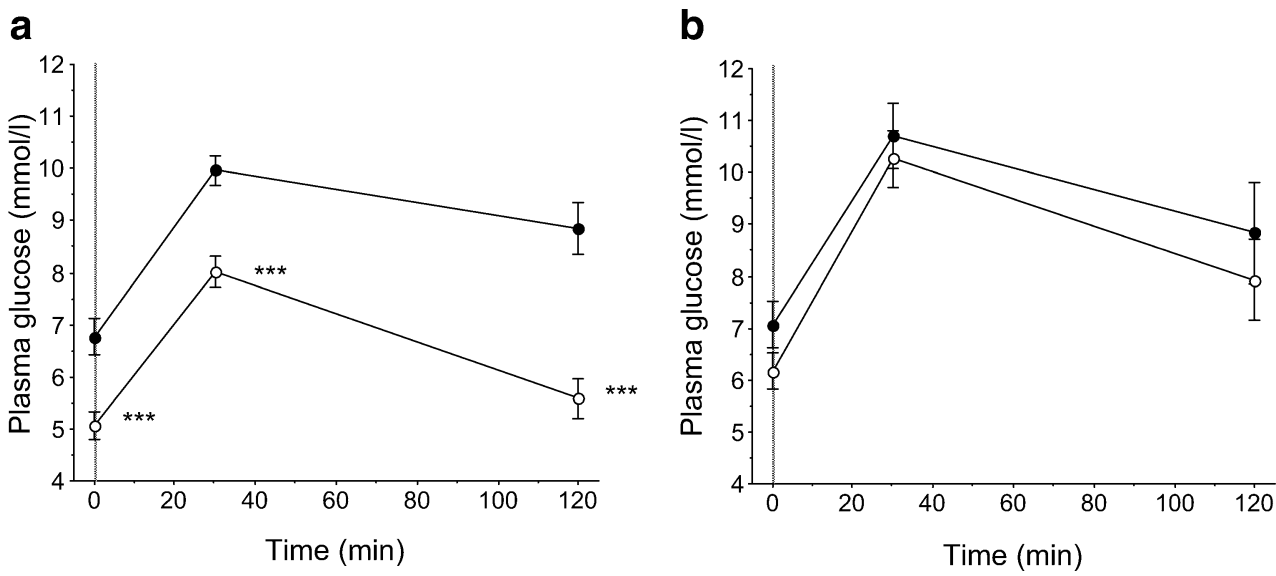


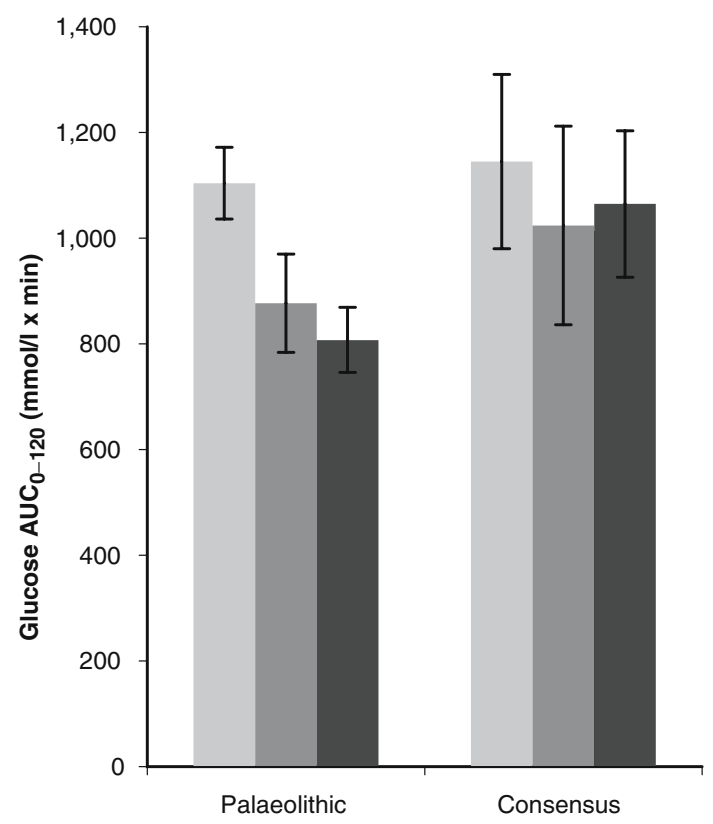

Fig. 2 Mean glucose AUCs (0-120 min) during OGTTs at study start (baseline, light grey columns) and after 6 weeks (dark grey columns) and 12 weeks (black columns) in the Palaeolithic and Consensus groups. Error bars denote 95\% CIs

$7 \%$ in the Consensus group $(p=0.10)$, and the difference between the groups was highly significant. After 12 weeks, all 14 subjects in the Palaeolithic group had normal values, compared with 7 of 15 subjects in the Consensus group ( $p=$ 0.0007 for group difference; Table 4). At 12 weeks, five subjects in the Consensus group still had diabetic values.

There was a decrease of HOMA-IR in both groups with no significant difference between the two groups (Table 4). The QUICKI index of insulin sensitivity [1/(ln fasting plasma insulin + ln fasting plasma glucose)] did not change more in the Palaeolithic group than in the Consensus group $(p=0.23$, data not shown). The early phase of postchallenge glucose and insulin responses, as represented by
Incremental AUC Glucose $_{0-30}$ and Incremental AUC Insulin $_{0-30}$, did not change significantly during the trial, although a trend towards lowered Incremental AUC Insulin $0-30$ was seen in both groups (Table 4).

Reported food composition differed between the two groups such that subjects in the Palaeolithic group had a much lower intake of dairy products, cereals and oil/ margarine, and a higher intake of fruits and nuts (Table 5). The intake of vegetables, meat, meat products or fish did not differ significantly between the groups. Total fat intake was low with no difference between the groups (Table 6). Absolute protein intake was identical in the two groups while relative protein intake (as a percentage of total energy intake [E\%]) was higher in the Palaeolithic group. Absolute carbohydrate intake was $43 \%$ lower in the Palaeolithic group, and 23\% lower in terms of E\%. Glycaemic load was $47 \%$ lower in the Palaeolithic group and correlated strongly with cereal intake $(r=0.75, p<0.0001)$.

Energy intake was $25 \%$ lower in the Palaeolithic group $(p=0.004$; Table 6$)$ despite similar quantities of consumed food (by weight; Table 5). After adjustment for energy intake, the improvement of AUC Glucose $e_{0-120}$ was still larger in the Palaeolithic group ( $p=0.02$; Supplementary Table 2), while the larger waist loss, and the tendency for larger decrease of AUC Insulin ${ }_{0-120}$, compared with the Consensus group, disappeared (Supplementary Table 3).

In post hoc analysis among the whole study population, a positive association between intake of cereals and change in waist circumference explained $42 \%$ of waist loss among the whole study population ( $p=0.0003$; Supplementary Table 6 ), and $40 \%$ in the Consensus group alone $(p=0.016)$. In contrast, there was a negative correlation between fruit intake and change in waist circumference, which explained $21 \%$ of waist loss $(p=0.01)$. Each of these associations remained significant after adjustment for dietary assignment, energy intake, carbohydrate intake or glycaemic load (Supplementary Table 5). Thus, waist loss increased with increasing
Fig. 3 Plasma insulin during OGTTs at study start (baseline, closed circles) and after 12 weeks (open circles) in the Palaeolithic (a) and Consensus (b) groups. Values are means SE. ${ }^{*} p<0.05 ; * * p>0.01$

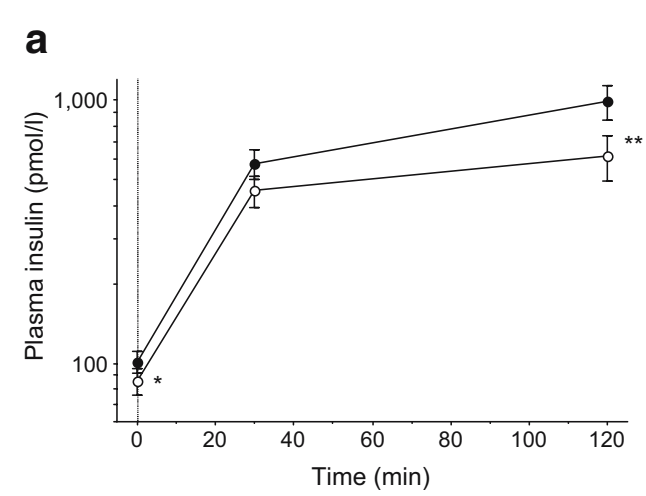

b

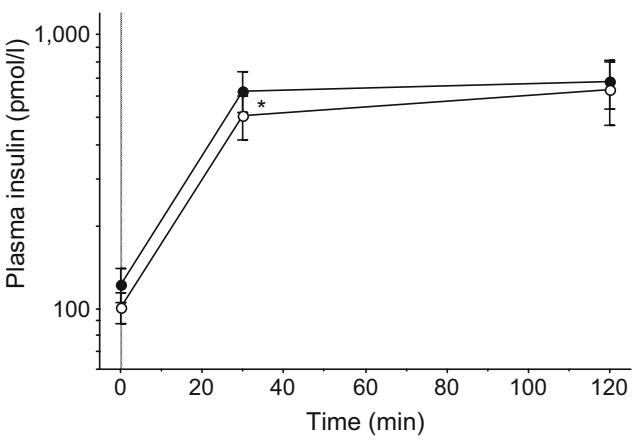


Table 3 Glucose and insulin responses to OGTTs (secondary outcome variables) during the trial
Values are means $\pm \mathrm{SD}$

${ }^{\mathrm{a}}$ For difference between groups

${ }^{*} p<0.01$ by paired $t$ test for change within group (6 week level is compared with baseline and 12 week level is compared with 6 week level)

$* * p<0.05$ by paired $t$ test for change within group (6 week level is compared with baseline and 12 week level is compared with 6 week level)
Group

$p$ value $^{\mathrm{a}}$

Palaeolithic $(n=14)$

Consensus $(n=15)$

\begin{tabular}{|c|c|c|c|}
\hline \multicolumn{4}{|l|}{ Fasting plasma glucose (mmol/1) } \\
\hline Baseline & $6.8 \pm 1.3$ & $7.1 \pm 1.8$ & 0.6 \\
\hline 6 weeks & $5.2 \pm 1.1^{*}$ & $5.8 \pm 1.2 * *$ & 0.2 \\
\hline 12 weeks & $5.1 \pm 1.0$ & $6.2 \pm 1.4$ & 0.02 \\
\hline Change $0-12$ weeks & $-1.7 \pm 1.7$ & $-0.9 \pm 1.8$ & 0.2 \\
\hline $95 \% \mathrm{CI}$ & -2.7 to -0.7 & -1.9 to +0.08 & \\
\hline$p$ value for change within group & 0.003 & 0.07 & \\
\hline \multicolumn{4}{|l|}{$30 \mathrm{~min}$ plasma glucose $(\mathrm{mmol} / \mathrm{l})$} \\
\hline Baseline & $10.0 \pm 1.1$ & $10.7 \pm 2.4$ & 0.3 \\
\hline 6 weeks & $8.4 \pm 1.6^{*}$ & $9.8 \pm 3.3$ & 0.16 \\
\hline 12 weeks & $8.0 \pm 1.1$ & $10.3 \pm 2.1$ & 0.001 \\
\hline Change $0-12$ weeks & $-2.0 \pm 1.2$ & $-0.4 \pm 1.6$ & 0.008 \\
\hline $95 \% \mathrm{CI}$ & -2.7 to -1.3 & -1.3 to +0.5 & \\
\hline$p$ value for change within group & 0.0001 & 0.3 & \\
\hline \multicolumn{4}{|l|}{120 min plasma glucose $(\mathrm{mmol} / \mathrm{l})$} \\
\hline Baseline & $8.9 \pm 1.8$ & $8.8 \pm 3.8$ & 1.0 \\
\hline 6 weeks & $6.6 \pm 1.5^{*}$ & $7.8 \pm 4.1$ & 0.3 \\
\hline 12 weeks & $5.6 \pm 1.5^{* *}$ & $7.9 \pm 3.1$ & 0.01 \\
\hline Change $0-12$ weeks & $-3.3 \pm 1.9$ & $-0.9 \pm 2.0$ & 0.003 \\
\hline $95 \% \mathrm{CI}$ & -4.4 to -2.2 & -2.0 to +0.2 & \\
\hline$p$ value for change within group & 0.0001 & 0.10 & \\
\hline \multicolumn{4}{|l|}{ Fasting plasma insulin $(\mathrm{pmol} / \mathrm{l})$} \\
\hline Baseline & $102 \pm 36$ & $123 \pm 68$ & 0.3 \\
\hline 6 weeks & $91 \pm 32$ & $100 \pm 45$ & 0.5 \\
\hline 12 weeks & $86 \pm 36$ & $101 \pm 53$ & 0.4 \\
\hline Change $0-12$ weeks & $-16 \pm 27$ & $-22 \pm 54$ & 0.7 \\
\hline $95 \% \mathrm{CI}$ & -32 to -0.3 & -51 to +8 & \\
\hline$p$ value for change within group & 0.047 & 0.15 & \\
\hline \multicolumn{4}{|l|}{30 min plasma insulin $(\mathrm{pmol} / \mathrm{l})$} \\
\hline Baseline & $575 \pm 290$ & $625 \pm 416$ & 0.7 \\
\hline 6 weeks & $503 \pm 222$ & $516 \pm 393$ & 0.9 \\
\hline 12 weeks & $453 \pm 226$ & $507 \pm 355$ & 0.7 \\
\hline Change $0-12$ weeks & $-121 \pm 230$ & $-118 \pm 202$ & 1.0 \\
\hline $95 \% \mathrm{CI}$ & -254 to +12 & -230 to -6 & \\
\hline$p$ value for change within group & 0.07 & 0.04 & \\
\hline \multicolumn{4}{|l|}{120 min plasma insulin $(\mathrm{pmol} / \mathrm{l})$} \\
\hline Baseline & $988 \pm 570$ & $674 \pm 532$ & 0.14 \\
\hline 6 weeks & $702 \pm 423 * *$ & $482 \pm 374 *$ & 0.15 \\
\hline 12 weeks & $615 \pm 443$ & $631 \pm 633$ & 1.0 \\
\hline Change $0-12$ weeks & $-374 \pm 408$ & $-42 \pm 408$ & 0.04 \\
\hline $95 \% \mathrm{CI}$ & -609 to -138 & -268 to +183 & \\
\hline$p$ value for change within group & 0.005 & 0.7 & \\
\hline
\end{tabular}

intake of fruits and decreasing intake of cereals, associations which explained most of the group difference in waist loss. Compared with waist change, weight change was generally less clearly associated with dietary assignment and other variables (Table 2, Supplementary Tables 2, 3, 4, 5 and 6).

Glycaemic load was positively associated with changes in waist $(r=0.52, p=0.008)$ and AUC Glucose ${ }_{0-120}(r=$ $0.50, p=0.01)$ but not with change in AUC Insulin ${ }_{0-120}(r=$ $0.30, p=0.15)$. When glycaemic load and dietary assign- ment were entered simultaneously as explanatory variables in bivariate linear regression, neither of these was significantly associated with change in AUC Glucose $_{0-120}$ (Supplementary Table 2). In forward stepwise linear regression with glycaemic load and dietary assignment as independent variables, only dietary assignment was associated with change in AUC Glucose ${ }_{0-120}$ (data not shown).

None of the other effects, nor lack of effects, of group assignment on primary outcome variables (changes in weight, 
Table 4 Other glucometabolic variables in the two groups
Values are means $\pm \mathrm{SD}$

${ }^{*} p<0.05$ by paired $t$ test

for change within group

(6 week level is compared with

baseline and 12 week level

is compared with 6 week level)

${ }^{\mathrm{a}}$ For difference between

groups

${ }^{\mathrm{b}}$ Fasting venous plasma

glucose $\leq 6.0 \mathrm{mmol} / 1$ and

$2 \mathrm{~h}$ venous plasma glucose

$<7.8 \mathrm{mmol} / \mathrm{l}$ at OGTT

(despite increased capillary

blood glucose at screening)

${ }^{\mathrm{c}}$ Fasting venous plasma

glucose $\geq 7.0 \mathrm{mmol} / 1$ or $2 \mathrm{~h}$

venous plasma glucose

$\geq 11.1 \mathrm{mmol} / \mathrm{l}$ at OGTT

${ }^{\mathrm{d}}$ Incremental $\mathrm{AUC}_{0-30}$, incremental AUC during the first

$30 \mathrm{~min}$ of OGTT, using levels at $0 \mathrm{~min}$ as the base of the area

\begin{tabular}{|c|c|c|c|}
\hline & \multicolumn{2}{|l|}{ Group } & \multirow[t]{2}{*}{$p$ value } \\
\hline & Palaeolithic $(n=14)$ & Consensus $(n=15)$ & \\
\hline \multicolumn{4}{|l|}{$\mathrm{HbA}_{1 \mathrm{c}}(\%)$} \\
\hline Baseline & $4.76 \pm 0.26$ & $4.89 \pm 0.79$ & 0.6 \\
\hline 6 weeks & $4.61 \pm 0.25^{*}$ & $4.84 \pm 0.72$ & 0.3 \\
\hline 12 weeks & $4.64 \pm 0.22$ & $4.85 \pm 0.69$ & 0.3 \\
\hline Change $0-12$ weeks & $-0.13 \pm 0.26$ & $-0.03 \pm 0.39$ & 0.4 \\
\hline $95 \% \mathrm{CI}$ & -0.28 to +0.02 & -0.24 to +0.17 & \\
\hline$p$ value for change within group & 0.09 & 0.7 & \\
\hline \multicolumn{4}{|l|}{ Normal glucose levels ${ }^{\mathrm{b}}(n)$} \\
\hline Baseline & 2 & 2 & 0.8 \\
\hline 6 weeks & 10 & 10 & 0.7 \\
\hline 12 weeks & 14 & 7 & 0.0007 \\
\hline \multicolumn{4}{|l|}{ Diabetic glucose levels $^{\mathrm{c}}(n)$} \\
\hline Baseline & 10 & 9 & 0.4 \\
\hline 6 weeks & 1 & 3 & 0.2 \\
\hline 12 weeks & 0 & 5 & 0.01 \\
\hline \multicolumn{4}{|l|}{ ln HOMA-IR } \\
\hline Baseline & $0.62 \pm 0.38$ & $0.75 \pm 0.53$ & 0.5 \\
\hline 6 weeks & $0.47 \pm 0.33^{*}$ & $0.55 \pm 0.42 *$ & 0.6 \\
\hline 12 weeks & $0.39 \pm 0.36$ & $0.55 \pm 0.46$ & 0.3 \\
\hline Change $0-12$ weeks & $-0.24 \pm 0.29$ & $-0.19 \pm 0.36$ & 0.7 \\
\hline $95 \% \mathrm{CI}$ & -0.40 to -0.07 & -0.39 to +0.01 & \\
\hline$p$ value for change within group & 0.01 & 0.03 & \\
\hline \multicolumn{4}{|l|}{ Insulin/Glucose ${ }_{0-30}$} \\
\hline Baseline & $172 \pm 125$ & $145 \pm 110$ & 0.5 \\
\hline 6 weeks & $135 \pm 61$ & $133 \pm 144$ & 1.0 \\
\hline 12 weeks & $139 \pm 72$ & $112 \pm 126$ & 0.5 \\
\hline Change $0-12$ weeks & $-33 \pm 94$ & $-33 \pm 71$ & 1.0 \\
\hline $95 \% \mathrm{CI}$ & -87 to +21 & -73 to +8 & \\
\hline$p$ value for change within group & 0.2 & 0.11 & \\
\hline \multicolumn{4}{|l|}{ Incremental Glucose $\mathrm{AUC}_{0-30}{ }^{\mathrm{d}}$} \\
\hline Baseline & $48 \pm 20$ & $54 \pm 20$ & 0.4 \\
\hline 6 weeks & $48 \pm 19$ & $60 \pm 40$ & 0.3 \\
\hline 12 weeks & $44 \pm 20$ & $62 \pm 26$ & 0.06 \\
\hline Change $0-12$ weeks & $-4 \pm 24$ & $+7 \pm 21$ & 0.19 \\
\hline $95 \% \mathrm{CI}$ & -18 to +10 & -4 to +19 & \\
\hline$p$ value for change within group & 0.6 & 0.2 & \\
\hline \multicolumn{4}{|l|}{ Incremental Insulin $\mathrm{AUC}_{0-30} \mathrm{~d}$} \\
\hline Baseline & $7.1 \pm 4.0$ & $7.5 \pm 5.9$ & 0.8 \\
\hline 6 weeks & $6.2 \pm 3.0$ & $6.2 \pm 5.6$ & 1.0 \\
\hline 12 weeks & $5.5 \pm 2.9$ & $6.1 \pm 4.8$ & 0.7 \\
\hline Change $0-12$ weeks & $-1.6 \pm 3.1$ & $-1.5 \pm 2.7$ & 0.9 \\
\hline $95 \% \mathrm{CI}$ & -3.4 to +0.2 & -3.0 to +0.07 & \\
\hline$p$ value for change within group & 0.08 & 0.06 & \\
\hline
\end{tabular}

waist, AUC Glucose ${ }_{0-120}$ and AUC Insulin $_{0-120}$ ) was essentially altered after adjustment for age or baseline levels of weight, waist, glucose, insulin, AUC Glucose $_{0-120}$ or AUC Insulin ${ }_{0-120}$, nor after adjustment for intake (g/day or $\mathrm{E} \%$ ) of carbohydrate, protein, total fat, saturated fat, monounsaturated fat, polyunsaturated fat, fibre or sodium. Repeated-measures ANOVA gave similar results for primary and secondary outcome variables, and addition of baseline values as covariates confirmed the independent effect of Palaeolithic diet on improvement of glucose tolerance (data not shown). Serum lipids changed to a similar extent in both groups, due to initiation of statin treatment in most patients, and there was no decrease in blood pressure (data not shown). The impact of medication was not analysed.

Among the 15 subjects who underwent BIA for body composition, change of fat mass did not differ between the groups (Table 7), and it explained $50 \%$ of weight change ( $p=$ 
Table 5 Diet composition (g/day) in the two groups, as estimated from 4 day weighed food records

\begin{tabular}{|c|c|c|c|}
\hline & \multicolumn{2}{|l|}{ Group } & \multirow{2}{*}{$\begin{array}{l}p \\
\text { value }^{\mathrm{a}}\end{array}$} \\
\hline & $\begin{array}{l}\text { Palaeolithic } \\
(n=14)\end{array}$ & $\begin{array}{l}\text { Consensus } \\
(n=15)\end{array}$ & \\
\hline Fruits & $493 \pm 335$ & $252 \pm 179$ & 0.03 \\
\hline Vegetables $^{\mathrm{b}}$ & $327 \pm 233$ & $202 \pm 88$ & 0.07 \\
\hline Potatoes & $51 \pm 42$ & $77 \pm 78$ & 0.3 \\
\hline Nuts & $11 \pm 12$ & $2 \pm 6$ & 0.02 \\
\hline Meat, fresh & $143 \pm 95$ & $97 \pm 67$ & 0.16 \\
\hline Meat products & $65 \pm 59$ & $58 \pm 49$ & 0.8 \\
\hline Fish & $119 \pm 92$ & $77 \pm 56$ & 0.16 \\
\hline Eggs & $29 \pm 23$ & $19 \pm 18$ & 0.21 \\
\hline Beans, peas & $8 \pm 21$ & $15 \pm 26$ & 0.5 \\
\hline Cereals & $18 \pm 52$ & $268 \pm 96$ & 0.0001 \\
\hline Milk and dairy products & $45 \pm 119$ & $287 \pm 193$ & 0.0006 \\
\hline Oil, margarine $\mathrm{e}^{\mathrm{c}}$ & $1 \pm 3$ & $16 \pm 11$ & 0.0001 \\
\hline Sauce & $2 \pm 6$ & $25 \pm 31$ & 0.02 \\
\hline Pastry & $1 \pm 3$ & $13 \pm 25$ & 0.12 \\
\hline Jam & $1 \pm 3$ & $6 \pm 10$ & 0.12 \\
\hline Total amount of food & $1,311 \pm 598$ & $1,382 \pm 222$ & 0.7 \\
\hline Wine & $59 \pm 63$ & $37 \pm 51$ & 0.3 \\
\hline Beer, light ${ }^{d}$ & $11 \pm 27$ & $27 \pm 47$ & 0.3 \\
\hline $\begin{array}{l}\text { Sweet beverages } \\
\text { (excluding juice) }\end{array}$ & $18 \pm 46$ & $53 \pm 90$ & 0.2 \\
\hline Juice & $38 \pm 75$ & $88 \pm 141$ & 0.3 \\
\hline
\end{tabular}

Values are means $\pm \mathrm{SD}$

${ }^{\text {a }}$ For difference between groups

${ }^{\mathrm{b}}$ Including root vegetables (but excluding potatoes and beans with pods)

${ }^{\mathrm{c}}$ Butter was not reported to be consumed by anyone

${ }^{\mathrm{d}}$ Stronger beer or liquor was not consumed, as reported

0.002). In this subset of patients, change in fat mass explained $<1 \%$ of change in AUC Glucose $\mathrm{A}_{0-120}$.

\section{Discussion}

We found marked improvement of glucose tolerance after advice to eat a Palaeolithic diet, based on lean meat, fish, fruits, vegetables, root vegetables, eggs and nuts as staple foods, while avoiding cereals, dairy products, refined fat, sugar and salt. Control subjects, who were advised to follow a Consensus (Mediterranean-like) diet based on whole grains, low-fat dairy products, fish, fruits and vegetables, did not significantly improve their glucose tolerance despite decreases in weight and waist circumference. The more pronounced improvement of glucose tolerance in the Palaeolithic group was unrelated to weight loss or decrease in waist circumference. In contrast, the insulin response changed more as a result of change in waist circumference than of dietary assignment or food choice.
Table 6 Daily intake of macronutrients, dietary fibre, cholesterol, sodium, potassium, magnesium and calcium in the two groups, as estimated from 4 day weighed food records

\begin{tabular}{|c|c|c|c|}
\hline & \multicolumn{2}{|l|}{ Group } & \multirow[t]{2}{*}{$p$ value $^{\mathrm{a}}$} \\
\hline & $\begin{array}{l}\text { Palaeolithic } \\
(n=14)\end{array}$ & $\begin{array}{l}\text { Consensus } \\
(n=15)\end{array}$ & \\
\hline \multicolumn{4}{|l|}{ Energy } \\
\hline MJ & $5.6 \pm 2.2$ & $7.5 \pm 1.3$ & \\
\hline kcal & $1,344 \pm 521$ & $1,795 \pm 306$ & 0.01 \\
\hline \multicolumn{4}{|l|}{ Protein } \\
\hline $\mathrm{g}$ & $90 \pm 41$ & $89 \pm 20$ & 0.9 \\
\hline $\mathrm{g} / \mathrm{kg}$ body weight & $0.98 \pm 0.4$ & $0.95 \pm 0.2$ & 0.8 \\
\hline $\mathrm{E} \%$ & $27.9 \pm 6.8$ & $20.5 \pm 3.6$ & 0.002 \\
\hline \multicolumn{4}{|l|}{ Total fat } \\
\hline $\mathrm{g}$ & $42 \pm 20$ & $50 \pm 13$ & 0.2 \\
\hline $\mathrm{g} / \mathrm{kg}$ body weight & $0.44 \pm 0.2$ & $0.55 \pm 0.2$ & 0.12 \\
\hline $\mathrm{E} \%$ & $26.9 \pm 6.4$ & $24.7 \pm 4.3$ & 0.3 \\
\hline \multicolumn{4}{|l|}{ Fatty acids } \\
\hline Saturated (g) & $11.5 \pm 4.8$ & $16.8 \pm 4.2$ & 0.005 \\
\hline $\mathrm{E} \%$ & $7.7 \pm 2.4$ & $8.3 \pm 1.7$ & 0.4 \\
\hline Monounsaturated (g) & $16.3 \pm 7.4$ & $19.0 \pm 5.0$ & 0.3 \\
\hline $\mathrm{E} \%$ & $10.7 \pm 2.6$ & $9.4 \pm 1.9$ & 0.2 \\
\hline Polyunsaturated (g) & $9.6 \pm 7.5$ & $9.0 \pm 3.0$ & 0.8 \\
\hline $\mathrm{E} \%$ & $5.8 \pm 2.5$ & $4.4 \pm 1.1$ & 0.06 \\
\hline \multicolumn{4}{|l|}{ Carbohydrate } \\
\hline $\mathrm{g}$ & $134 \pm 56$ & $231 \pm 48$ & 0.0001 \\
\hline $\mathrm{g} / \mathrm{kg}$ body weight & $1.4 \pm 0.6$ & $2.5 \pm 0.6$ & 0.0001 \\
\hline $\mathrm{E} \%$ & $40.2 \pm 8.3$ & $51.7 \pm 5.3$ & 0.0002 \\
\hline Glycaemic load $^{\mathrm{b}}$ & $65 \pm 30$ & $122 \pm 28$ & 0.0001 \\
\hline Alcohol (E\%) & $3.9 \pm 4.4$ & $2.3 \pm 3.0$ & 0.3 \\
\hline Fibre (g) & $21.4 \pm 13.2$ & $26.8 \pm 7.4$ & 0.2 \\
\hline Cholesterol (mg) & $397 \pm 192$ & $295 \pm 122$ & 0.11 \\
\hline \multicolumn{4}{|l|}{ Salt (g) } \\
\hline Sodium & $1.9 \pm 0.6$ & $2.9 \pm 0.7$ & 0.0006 \\
\hline Sodium chloride & $4.7 \pm 1.6$ & $7.2 \pm 1.7$ & 0.0006 \\
\hline
\end{tabular}

Values are means $\pm \mathrm{SD}$

${ }^{\mathrm{a}}$ For difference between groups

${ }^{\mathrm{b}}$ The Glycaemic Index (with glucose as the reference food) multiplied by the amount of carbohydrate

The higher drop-out rate in the Palaeolithic group (three vs none) does not appear to be an important source of bias. If we assume no change in primary outcome variables in any of the drop-out subjects, had they finished the trial, we would still have found larger decreases in AUC Glucose ${ }_{0-120}(p=$ $0.01)$ and $2 \mathrm{~h}$ glucose $(p=0.02)$ in the Palaeolithic group than in the Consensus group.

It is conceivable, but not very likely, that the more pronounced improvement of glucose tolerance in the Palaeolithic group was due to higher motivation (rather than different food patterns). We were meticulous in our efforts not to give the subjects in the Consensus group a feeling of belonging to a control group. Thus, we told eligible persons that we were to compare two healthy diets, 
Table 7 Leg-to-leg BIA in a subset of patients $(n=15)$

Values are means $\pm \mathrm{SD}$

${ }^{\mathrm{a}}$ For difference between groups

${ }^{*} p<0.05$ by paired $t$ test for change within group (6 week level is compared with baseline and 12 week level is compared with 6 week level)

$* * p<0.01$ by paired $t$ test for change within group (6 week level is compared with baseline and 12 week level is compared with 6 week level)

\begin{tabular}{|c|c|c|c|}
\hline & \multicolumn{2}{|l|}{ Group } & \multirow[t]{2}{*}{$p$ value } \\
\hline & Palaeolithic $(n=8)$ & Consensus $(n=7)$ & \\
\hline \multicolumn{4}{|l|}{ Fat mass $(\mathrm{kg})$} \\
\hline Baseline & $28.7 \pm 5.4$ & $33.0 \pm 8.6$ & 0.3 \\
\hline 6 weeks & $26.5 \pm 4.5^{*}$ & $31.7 \pm 8.5^{*}$ & 0.16 \\
\hline 12 weeks & $24.9 \pm 4.5^{*}$ & $30.8 \pm 8.7$ & 0.12 \\
\hline Change $0-12$ weeks & $-3.9 \pm 2.9$ & $-2.3 \pm 1.0$ & 0.18 \\
\hline $95 \% \mathrm{CI}$ & -6.3 to -1.5 & -3.2 to -1.4 & \\
\hline$p$ value for change within group & 0.007 & 0.0009 & \\
\hline \multicolumn{4}{|l|}{ Fat mass ( $\%$ of body mass) } \\
\hline Baseline & $30.0 \pm 3.0$ & $32.6 \pm 5.7$ & 0.3 \\
\hline 6 weeks & $28.9 \pm 2.7$ & $31.8 \pm 5.6^{*}$ & 0.2 \\
\hline 12 weeks & $27.4 \pm 2.7 * *$ & $31.0 \pm 5.9$ & 0.14 \\
\hline Change $0-12$ weeks & $-2.6 \pm 2.3$ & $-1.6 \pm 0.6$ & 0.3 \\
\hline $95 \% \mathrm{CI}$ & -4.5 to -0.7 & -2.2 to -1.1 & \\
\hline$p$ value for change within group & 0.02 & 0.0004 & \\
\hline \multicolumn{4}{|l|}{ Fat-free mass $(\mathrm{kg})$} \\
\hline Baseline & $66.6 \pm 6.3$ & $66.7 \pm 4.8$ & 1.0 \\
\hline 6 weeks & $64.8 \pm 6.1$ & $66.6 \pm 4.9$ & 0.5 \\
\hline 12 weeks & $65.6 \pm 6.6^{*}$ & $66.9 \pm 4.9$ & 0.7 \\
\hline Change $0-12$ weeks & $-1.0 \pm 2.7$ & $+0.2 \pm 0.9$ & 0.3 \\
\hline $95 \% \mathrm{CI}$ & -3.3 to +1.3 & -0.7 to +1.0 & \\
\hline$p$ value for change within group & 0.3 & 0.6 & \\
\hline \multicolumn{4}{|l|}{ Total body water $(\mathrm{kg})$} \\
\hline Baseline & $48.7 \pm 4.6$ & $48.8 \pm 3.5$ & 1.0 \\
\hline 6 weeks & $47.4 \pm 4.5$ & $48.7 \pm 3.6$ & 0.6 \\
\hline 12 weeks & $48.0 \pm 4.8^{*}$ & $49.0 \pm 3.6$ & 0.7 \\
\hline Change $0-12$ weeks & $-0.7 \pm 2.0$ & $+0.2 \pm 0.7$ & 0.3 \\
\hline $95 \% \mathrm{CI}$ & -2.4 to +0.9 & -0.5 to +0.8 & \\
\hline$p$ value for change within group & 0.3 & 0.5 & \\
\hline
\end{tabular}

not knowing which was the better one. We informed all subjects individually of the presumed benefits of their respective diet (but not of those of the other diet) during two $1 \mathrm{~h}$ sessions, and all subjects were provided with recipes and written dietary advice of equal length. During the 12 week trial, waist circumference decreased more in the Palaeolithic group, but this did not explain the more pronounced decrease in fasting and post-prandial plasma glucose in these subjects.

Among the whole study population, change in AUC Glucose $_{0-120}$ was not related to changes in weight or waist circumference. Considering the large variation in weight loss (between -10.7 and $+1.3 \mathrm{~kg}$ ), and in light of earlier studies showing weight loss to be the major determinant of improved glucose tolerance [12], this lack of relationship is unexpected. In the Diabetes Prevention Project, weight loss was the dominant predictor of reduced diabetes incidence among glucose-intolerant subjects who were randomised to lifestyle modification [37]. However, weight change does not explain all of the improvement in glucose tolerance in such trials, and in a meta-analysis on the efficacy of lifestyle education to prevent type 2 diabetes in high-risk individuals, four out of eight trials did not find any effect on $2 \mathrm{~h}$ plasma glucose despite significant weight loss [12]. Furthermore, in epidemiological studies most of the variation in glucose tolerance among the general population is not explained by adiposity [38]. Therefore, an improvement in glucose tolerance that is independent of weight change is not entirely unexpected.

There was no apparent influence of dietary assignment on the HOMA-IR index of insulin sensitivity, and adjustment for changes in waist circumference or body weight eliminated the tendency towards larger decrease of AUC Insulin $_{0-120}$ in the Palaeolithic group. This is in contrast to a recent feeding trial in pigs, where we found markedly lower insulin response by the frequently sampled IVGTT, independent of body weight, after 15 months of a cerealfree Palaeolithic diet, compared with a cereal-based swine feed [39]. This discrepancy may be due to the use of frequently sampled IVGTT in the study in pigs, which gives a more precise measure of insulin sensitivity than that of the present study (HOMA-IR). Since we did not perform euglycaemic insulin clamp measurements, the gold standard for assessing whole-body insulin sensitivity, we may have 
missed a significant effect on insulin sensitivity. If not, our findings add to the evidence that reduction of waist circumference is more important than dietary composition for the treatment of insulin resistance [19].

The very low reported energy intake in the Palaeolithic group, as calculated from 4 day weighed food records (registered early in the trial), does not necessarily imply under-reporting of food intake. An energy deficit of $4 \mathrm{MJ} /$ day would be expected to cause a weight loss of $1 \mathrm{~kg} /$ week in the second and third months of energy restriction, and even more during the first month [40]. Thus, assuming a pre-study energy intake of at least $10 \mathrm{MJ} /$ day, the reported in-trial energy intake is actually higher than expected from the observed weight loss, even in the Palaeolithic group. In addition, the similar weight loss in the two groups is not incompatible with different energy intakes. In this context, the laws of thermodynamics need to be considered thoroughly. These laws state that energy is constant and cannot be destroyed. However, they also state that energy can take various forms, including heat, and that conversion from one form of energy to another is more or less efficient [41]. Highly relevant, then, is the finding in animal experiments of decreased body temperature on low-calorie diets [42, 43]. Accordingly, identical weight loss on different energy intakes does not violate the laws of thermodynamics [41].

It is important to separate glycaemic control, as measured by $\mathrm{HbA}_{1 \mathrm{c}}$, from glucose tolerance. A habitual diet which reduces the post-prandial glucose response, such as a low glycaemic load diet, can reduce the metabolic consequences of glucose intolerance, including delaying the manifestation of diabetes, without necessarily improving glucose tolerance itself $[19,44]$. Although we cannot rule out glycaemic load as an important factor for glucose tolerance, our finding that the effect of Palaeolithic diet on glucose tolerance was independent of carbohydrate intake agrees with earlier studies which do not indicate a beneficial effect of carbohydrate restriction on glucose tolerance [20, 45-47].

The high fruit intake in the Palaeolithic group, almost sevenfold higher than the median intake among Swedish men (75 g/day) [48], and twice as high as in the Consensus group, should also be viewed against this background. Despite large variation in fruit intake (range 160-1,435 g/day in the Palaeolithic group and 53-679 g/day in the Consensus group), it was not associated with change in AUC Glucose $_{0-120}(r=-0.02, p=0.9)$ or AUC $\operatorname{Insulin}_{0-120}(r=$ $-0.02, p=0.9)$ and did not explain the effects of group assignment on these outcome variables. Furthermore, a high fruit intake was associated with larger waist loss. Thus, our study lends no support to the notion that fruit intake should be restricted in patients with diabetes or glucose intolerance.
This is, to the best of our knowledge, the first controlled study of the effects of an ancestral human diet in patients with IGT or diabetes. In a non-controlled study of ten Australian Aborigines with diabetes and a mean BMI of 27 $\mathrm{kg} / \mathrm{m}^{2}$, O'Dea et al. found that reversion to a huntergatherer lifestyle during 7 weeks led to $10 \%$ weight loss and reductions in fasting and $2 \mathrm{~h}$ glucose of 45 and $36 \%$ $(p<0.0001$ for all) [49]. Fasting insulin decreased by $48 \%$ $(p<0.0001)$, while $2 \mathrm{~h}$ insulin did not change $(+20 \%$, not significant). Both diet and physical activity changed markedly, which precludes evaluation about the isolated role of diet. In contrast, in a similar study on healthy Australian Aborigines by the same authors, the insulin response to $70 \mathrm{~g}$ of starch from white bread (and butter) was reduced, while the glucose response was not, after 10-12 weeks of reversion to a traditional lifestyle [50].

In conclusion, we found marked improvement of glucose tolerance in IHD patients with increased blood glucose or diabetes after advice to follow a Palaeolithic diet compared with a healthy Western diet. The larger improvement of glucose tolerance in the Palaeolithic group was independent of energy intake and macronutrient composition, which suggests that avoiding Western foods is more important than counting calories, fat, carbohydrate or protein. The study adds to the notion that healthy diets based on wholegrain cereals and low-fat dairy products are only the second best choice in the prevention and treatment of type 2 diabetes.

Acknowledgements The study was funded by Region Skåne and Lund University.

Duality of interest The authors declare that there is no duality of interest associated with this manuscript.

\section{References}

1. Nielson C, Lange T, Hadjokas N (2006) Blood glucose and coronary artery disease in nondiabetic patients. Diabetes Care 29:998-1001

2. Brunner EJ, Shipley MJ, Witte DR, Fuller JH, Marmot MG (2006) Relation between blood glucose and coronary mortality over 33 years in the Whitehall Study. Diabetes Care 29:26-31

3. Bartnik M, Malmberg K, Norhammar A, Tenerz A, Ohrvik J, Ryden L (2004) Newly detected abnormal glucose tolerance: an important predictor of long-term outcome after myocardial infarction. Eur Heart J 25:1990-1997

4. Fisman EZ, Motro M, Tenenbaum A, Boyko V, Mandelzweig L, Behar S (2001) Impaired fasting glucose concentrations in nondiabetic patients with ischemic heart disease: a marker for a worse prognosis. Am Heart J 141:485-490

5. Norhammar A, Tenerz A, Nilsson G et al (2002) Glucose metabolism in patients with acute myocardial infarction and no previous diagnosis of diabetes mellitus: a prospective study. Lancet 359:2140-2144 
6. Bartnik M, Ryden L, Ferrari R et al (2004) The prevalence of abnormal glucose regulation in patients with coronary artery disease across Europe. The Euro Heart Survey on diabetes and the heart. Eur Heart J 25:1880-1890

7. Hashimoto K, Ikewaki K, Yagi H et al (2005) Glucose intolerance is common in Japanese patients with acute coronary syndrome who were not previously diagnosed with diabetes. Diabetes Care 28:1182-1186

8. Ishihara $M$, Inoue $I$, Kawagoe $T$ et al (2006) Is admission hyperglycaemia in non-diabetic patients with acute myocardial infarction a surrogate for previously undiagnosed abnormal glucose tolerance? Eur Heart J 27:2413-2419

9. Hu DY, Pan CY, Yu JM (2006) The relationship between coronary artery disease and abnormal glucose regulation in China: the China Heart Survey. Eur Heart J 27:2573-2579

10. Johansen OE, Birkeland KI, Brustad E et al (2006) Undiagnosed dysglycaemia and inflammation in cardiovascular disease. Eur $\mathrm{J}$ Clin Investig 36:544-551

11. Harding SA, Anscombe R, Weatherall M, Prasad S, Lever N, Krebs J (2006) Abnormal glucose metabolism and features of the metabolic syndrome are common in patients presenting for elective cardiac catheterization. Intern Med J 36:759-764

12. Yamaoka K, Tango T (2005) Efficacy of lifestyle education to prevent type 2 diabetes: a meta-analysis of randomized controlled trials. Diabetes Care 28:2780-2786

13. Knowler WC, Barrett-Connor E, Fowler SE et al (2002) Reduction in the incidence of type 2 diabetes with lifestyle intervention or metformin. N Engl J Med 346:393-403

14. Tuomilehto J, Lindstrom J, Eriksson JG et al (2001) Prevention of type 2 diabetes mellitus by changes in lifestyle among subjects with impaired glucose tolerance. N Engl J Med 344:1343-1350

15. De Backer G, Ambrosioni E, Borch-Johnsen K et al (2003) European guidelines on cardiovascular disease prevention in clinical practice. Third Joint Task Force of European and Other Societies on Cardiovascular Disease Prevention in Clinical Practice. Eur Heart J 24:1601-1610

16. Mann JI, De Leeuw I, Hermansen K et al (2004) Evidence-based nutritional approaches to the treatment and prevention of diabetes mellitus. Nutr Metab Cardiovasc Dis 14:373-394

17. Franz MJ, Bantle JP, Beebe CA et al (2002) Evidence-based nutrition principles and recommendations for the treatment and prevention of diabetes and related complications. Diabetes Care 25:148-198

18. Kennedy RL, Chokkalingam K, Farshchi HR (2005) Nutrition in patients with type 2 diabetes: are low-carbohydrate diets effective, safe or desirable? Diabet Med 22:821-832

19. Reaven GM (2005) The insulin resistance syndrome: definition and dietary approaches to treatment. Annu Rev Nutr 25:391406

20. Noakes M, Foster PR, Keogh JB, James AP, Mamo JC, Clifton PM (2006) Comparison of isocaloric very low carbohydrate/high saturated fat and high carbohydrate/low saturated fat diets on body composition and cardiovascular risk. Nutr Metab (Lond) 3:7

21. Lavigne C, Tremblay F, Asselin G, Jacques H, Marette A (2001) Prevention of skeletal muscle insulin resistance by dietary cod protein in high fat-fed rats. Am J Physiol Endocrinol Metab 281: E62-E71

22. Vasankari TJ, Vasankari TM (2006) Effect of dietary fructose on lipid metabolism, body weight and glucose tolerance in humans. Scand J Food Nutr 50:55-63

23. Petrie JR, Morris AD, Minamisawa K et al (1998) Dietary sodium restriction impairs insulin sensitivity in noninsulin-dependent diabetes mellitus. J Clin Endocrinol Metab 83:1552-1557

24. Donovan DS, Solomon CG, Seely EW, Williams GH, Simonson DC (1993) Effect of sodium intake on insulin sensitivity. Am J Physiol 264:E730-734
25. Eaton S, Konner M (1985) Paleolithic nutrition. A consideration of its nature and current implications. N Engl J Med 312:283-289

26. Lindeberg S, Cordain L, Eaton SB (2003) Biological and clinical potential of a palaeolithic diet. J Nutr Environ Med 13:1-12

27. Lindeberg S, Lundh B (1993) Apparent absence of stroke and ischaemic heart disease in a traditional Melanesian island: a clinical study in Kitava. J Intern Med 233:269-275

28. Lindeberg S, Nilsson-Ehle P, Terént A, Vessby B, Scherstén B (1994) Cardiovascular risk factors in a Melanesian population apparently free from stroke and ischaemic heart disease - the Kitava study. J Intern Med 236:331-340

29. Lindeberg S, Eliasson M, Lindahl B, Ahrén B (1999) Low serum insulin in traditional Pacific Islanders- the Kitava Study. Metabolism 48:1216-1219

30. de Lorgeril M, Renaud S, Mamelle N et al (1994) Mediterranean alpha-linolenic acid-rich diet in secondary prevention of coronary heart disease. Lancet 343:1454-1459

31. Lingfors H, Lindström K, Persson L-G et al (1994) Evaluation of a pedagogic dietary questionnaire aimed for health surveys. Scand J Nutr 38:106-111

32. Lingfors $\mathrm{H}$, Persson LG, Lindstrom $\mathrm{K}$, Ljungquist $\mathrm{B}$, Bengtsson $\mathrm{C}$ (2002) Time for a "vision zero" concerning premature death from ischaemic heart disease? Scand J Prim Health Care 20:28-32

33. Eaton SB, Strassman BI, Nesse RM et al (2002) Evolutionary health promotion. Prev Med 34:109-118

34. Levy JC, Matthews DR, Hermans MP (1998) Correct homeostasis model assessment (HOMA) evaluation uses the computer program. Diabetes Care 21:2191-2192

35. Foster-Powell K, Holt SH, Brand-Miller JC (2002) International table of glycemic index and glycemic load values: 2002. Am J Clin Nutr 76:5-56

36. Altman DG (1991) Practical statistics for medical research. Chapman \& Hall, London

37. Hamman RF, Wing RR, Edelstein SL et al (2006) Effect of weight loss with lifestyle intervention on risk of diabetes. Diabetes Care 29:2102-2107

38. McKeigue PM, Pierpoint T, Ferrie JE, Marmot MG (1992) Relationship of glucose intolerance and hyperinsulinaemia to body fat pattern in south Asians and Europeans. Diabetologia 35:785-791

39. Jönsson T, Ahren B, Pacini G et al (2006) A Paleolithic diet confers higher insulin sensitivity, lower C-reactive protein and lower blood pressure than a cereal-based diet in domestic pigs. Nutr Metab (Lond) 3:39

40. Garrow JS (2000) Obesity. In: Garrow JS, James WPT (eds) Human nutrition and dietetics. Churchill Livingstone, Edinburgh, pp 527-545

41. Feinman RD, Fine EJ (2004) "A calorie is a calorie" violates the second law of thermodynamics. Nutr J 3:9

42. Lane MA, Baer DJ, Rumpler WV et al (1996) Calorie restriction lowers body temperature in rhesus monkeys, consistent with a postulated anti-aging mechanism in rodents. Proc Natl Acad Sci USA 93:4159-4164

43. Saper CB (2006) Biomedicine. Life, the universe, and body temperature. Science 314:773-774

44. Gannon MC, Nuttall FQ (2006) Control of blood glucose in type 2 diabetes without weight loss by modification of diet composition. Nutr Metab (Lond) 3:16

45. Pittas AG, Roberts SB, Das SK et al (2006) The effects of the dietary glycemic load on type 2 diabetes risk factors during weight loss. Obesity (Silver Spring) 14:2200-2209

46. Nestel P, Cehun M, Chronopoulos A (2004) Effects of long-term consumption and single meals of chickpeas on plasma glucose, insulin, and triacylglycerol concentrations. Am J Clin Nutr 79:390-395

47. Vidon C, Boucher P, Cachefo A, Peroni O, Diraison F, Beylot M (2001) Effects of isoenergetic high-carbohydrate compared with 
high-fat diets on human cholesterol synthesis and expression of key regulatory genes of cholesterol metabolism. Am J Clin Nutr 73:878-884

48. Becker W, Pearson M (2002) Dietary habits and nutrient intake in Sweden 1997-98: the Second National Food Consumption Survey (in Swedish). Swedish National Food Administration, Uppsala
49. O'Dea K (1984) Marked improvement in carbohydrate and lipid metabolism in diabetic Australian aborigines after temporary reversion to traditional lifestyle. Diabetes 33:596-603

50. O'Dea K, Spargo RM, Akerman K (1980) The effect of transition from traditional to urban life-style on the insulin secretory response in Australian Aborigines. Diabetes Care 3:31-37 